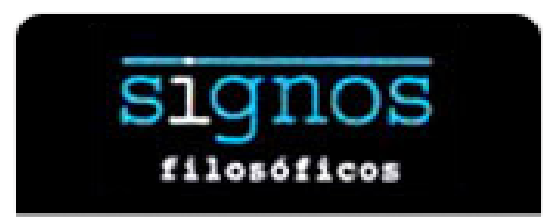

\section{t110soficos}

Signos Filosóficos

ISSN: 1665-1324

sifi@xanum.uam.mx

Universidad Autónoma Metropolitana Unidad Iztapalapa

México

Constante, Alberto

A propósito del Nietzsche de Heidegger

Signos Filosóficos, núm. 6, julio-diciembre, 2001, pp. 85-112

Universidad Autónoma Metropolitana Unidad Iztapalapa

Distrito Federal, México

Disponible en: http://www.redalyc.org/articulo.oa?id=34300603

- Cómo citar el artículo

- Número completo

- Más información del artículo

- Página de la revista en redalyc.org

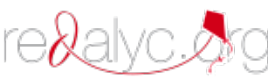

Sistema de Información Científica

Red de Revistas Científicas de América Latina, el Caribe, España y Portugal

Proyecto académico sin fines de lucro, desarrollado bajo la iniciativa de acceso abierto 
Signos filosóficos, núm. 6, julio-diciembre, 2001, 85-112

\title{
A propósito del Nietzsche de Heidegger
}

\author{
Alberto Constante* \\ Facultad de Filosofía y Letras, \\ Universidad Nacional Autónoma de México \\ Cada pensador piensa sólo un único pensamiento \\ MARTIN HEIDEGgeR
}

Palabras clave: ontología, metafísica, historia, replanteamiento, humanismo, consumación, voluntad

I.

in duda, una de las más grandes obras del maestro del pensamiento Martin - Heidegger es la dedicada a Nietzsche. Se trata de dos volúmenes que 1 recogen las lecciones de 1936 a 1940 en Friburgo y otras disertaciones de 1940 a 1946. Heidegger explica, en el prólogo, que esta obra representa su trayectoria mental desde 1930 a 1931 hasta la Carta sobre el humanismo (1947), es decir, el tiempo de transición hacia lo que los comentaristas han seguido llamando la segunda época o el segundo Heidegger. Éstas no son páginas meramente históricas, en ellas el pensador de Totnauberg lleva a cabo el intento de esclarecer el pensamiento de Nietzsche desde el nivel del propio pensar, un pensar que está in via y se beneficia del diálogo con el pensador del nihilismo.

*constanteorfeo@terra.com.mx 
Nietzsche no ha sido para Heidegger un mero pretexto (como puede aducirse, y en muchos casos, debido a la incomprensión, se ha hecho), un autor intercambiable con cualquier otro. Una de las tareas que Heidegger se impuso en Sein und Zeit fue la destrucción de la historia de la ontología, tarea, por demás, reservada a la segunda parte de la obra, aunque, como todos saben, quedó trunca. No obstante, el pensador de Messkirch no ha hecho otra cosa en el resto de su producción filosófica que destruir, desmontar como las piezas de un reloj la historia de la filosofía. En este sentido, no hay lugar a la extraña y ajena distinción entre las obras sistemáticas e históricas de Heidegger, entre destrucción y construcción; la historia de la metafísica es un elemento intrínseco del pensar heideggeriano, que es un pensar histórico, haciendo historia.

Que Heidegger haya dedicado tanta atención a un pensador como el filósofo de Basilea hace sospechar que no está de acuerdo con la imagen de Nietzsche comúnmente aceptada y consagrada. Esto es cierto. Nietzsche representa para Heidegger nada menos que la consumación de la metafísica occidental, su última plenitud; por eso ocuparse de Nietzsche es proseguir la tarea de destrucción y construcción, tema de su propia filosofía.

La idea de un Nietzsche como último resultado de la metafísica occidental choca, violentamente, con los tópicos reinantes en el mundillo filosófico. Heidegger no se cansa de repetir que Nietzsche sigue siendo un desconocido o, peor aún, un malentendido. Esto puede parecer extraño después del cúmulo de trabajos que han ido apareciendo sobre este pensador, más aún, en el centenario de su muerte, Por ello, Heidegger, en la época en que escribe su Nietzsche, advierte que se ha investigado mucho históricamente (historisch), pero se ha pensado poco. Repensar la obra de Nietzsche no es, por otra parte, una empresa fácil. Ya el hecho de que muchas de sus expresiones hayan pasado al acervo del habla cotidiana es un estorbo para devolver al lenguaje de Nietzsche su verdadero sentido e incorporarlo a su contexto real, que no es otro que el de la metafísica occidental. Por esa popularización del lenguaje y por su relativa proximidad a nosotros, es difícil entenderle y entablar un diálogo fructífero con él. "Cuanto más cerca temporalmente y casi contemporáneo nos es un pensador, tanto más largo es el camino hacia su pensamiento, tanto menos podemos ahorrarnos ese largo camino", dice el propio Heidegger.

El maestro de la Selva Negra teme que todavía no estemos preparados para entender, por ejemplo, una obra como Der Wille zur Macht; por eso aconsejaba a sus oyentes de Friburgo, en una lección de 1951, aplazar por ahora la lectura de Nietzsche y dedicarse durante diez o quince años al estudio de... Aristóteles. Esta 
invitación pudo aparecer como una broma, pero nada más contrario a la idea corriente y vigente de Nietzsche; lo corriente fácilmente se convierte en evidente y queda bajo la custodia de la sana razón, que se resiste tenazmente a revisar sus propias evidencias. En el caso de Nietzsche la sana razón es especialmente rebelde y pretenciosa; para ésta, lo que Nietzsche ha pensado y dicho es, por encima de exageraciones y oscuridades marginales, cosa clara y accesible a todo el mundo.

Heidegger opina, por el contrario, que no es nada fácil entender a un pensador de la talla de Nietzsche, ante todo, porque se trata de un auténtico pensador. Así, señala Heidegger, es difícil comprender a un pensador, no porque el pensador diga cosas complicadas y abstrusas, sino porque es difícil escucharle. Escuchar, esa operación tan simple, presupone algo que rara vez cumplimos, a saber, el reconocer. Reconocer consiste en abrirse a lo pensado por cada pensador como algo único, irrepetible e inagotable de tal modo que irrumpa en nosotros lo no pensado en su pensamiento. Para las evidencias de la sana razón lo no pensado de un pensar es simplemente lo ininteligible, que por cierto nunca es ocasión a la sana razón para dudar de su propia capacidad de comprensión o para recapacitar sobre sus propios límites.

\footnotetext{
Lo que menos es capaz de hacer la sana razón es reconocer. Pues el reconocimiento exige estar dispuestos a que nuestros propios esfuerzos pensantes queden desbaratados una y otra vez por lo no pensado que hay en el pensamiento de los pensadores
}

La postura fundamentalmente negativa (dagegengehen) comporta un empequeñecimiento de lo que hay de grande en un pensador, aunque se asegure, de paso, que fue un gran filósofo. "Tales elogios [dice Heidegger] desde abajo son en realidad ofensas".

Un Nietzsche — en la más rigurosa línea metafísica occidental— no sólo choca y molesta con la opinión generalizada, sino también con los profesionales de la filosofía. Heidegger exige que aprendamos a leer una obra como Also sprach Zarathustra “con el mismo rigor que un tratado de Aristóteles”. La demostración efectiva de esta tesis de Heidegger es la serie de lecciones y ensayos que componen la obra en dos volúmenes, donde trata de insertar a Nietzsche en la entraña misma de la más rigurosa tradición metafísica de Occidente y que hoy es presentada al público de habla hispana. 
EN CAMINO HACIA EL NIHILISMO

El primer encuentro eficaz de Heidegger con Nietzsche parece haber sido más bien tardío. Hasta las lecciones de 1936 en Friburgo no consta que se haya ocupado sistemáticamente de él. Tal vez el copioso material de Heidegger aún no publicado, especialmente en su labor de cátedra, nos obligaría a modificar esta idea. Tampoco se sabe qué es lo que determinó el primer encuentro de Heidegger con el Loco de Turín. Ciertamente no pudo ser la averiguación, lograda como fruto de un trato asiduo, aproximadamente a partir de 1936, de ser Nietzsche el resultado dialéctico de la experiencia metafísica de Occidente.

Tal vez, a modo de hipótesis, puedo aventurar que el concepto metafísico de nihilismo peculiar de Nietzsche pudo haber hecho impacto en el Heidegger de juventud, tal y como lo hubiera hecho la lectura de Duns Scoto. En Sein und Zeit y en la lección Was ist Metaphysik?, Heidegger concede a la noción de la nada una categoría $\mathrm{y}$, sobre todo, un enfoque que representaba una novedad en la historia de la filosofía. ${ }^{1}$ En la tradición metafísica occidental la nada era simplemente nada —nadería, nichtiges Nichts, comentaría Heidegger, la pura negación del ser. Heidegger, para recuperar el ser perdido en el ente y expresar su esencial carácter huidizo, comienza por situar, establecer y colocar la ecuación hegeliana de ser $=$ nada. $^{2}$

La relativamente temprana preocupación de Heidegger por la nada pudo haber despertado su creciente interés por el nihilismo de Nietzsche. El hecho es que desde la lección de 1940 Der europäische Nihilismus, Heidegger vuelve una y otra vez sobre esta expresión equívoca. Nietzsche había sido el primer pensador que la empleó con plena conciencia de su alcance metafísico y en un sentido que en su mente equivale a nihilismo occidental. Nietzsche entiende por tal un acontecimiento histórico que da carácter al siglo XIX, pero viene preparándose siglos atrás; Nietzsche lo resume en la estridente fórmula Dios ha muerto. Esta formulación del nihilismo es bastante ambigua y puede desorientar. Lo cierto es que la noción misma de nihilismo está aquejada de la misma ambigüedad, como ocurre con todos los términos vulgarizados.

\footnotetext{
${ }^{1}$ Desde luego por lo menos hasta los idealistas alemanes y dejando aparte a los místicos, sin descartar los enfoques que había llevado a cabo Bergson y un poco más lejos en el tiempo, Leibniz.

${ }^{2}$ Para efectos de este comentario de la obra de Heidegger, no creo necesario recordar la confusión que se creó en torno a esta nada que desorientó a los mejores intérpretes y fue ocasión de que Heidegger quedara catalogado como pensador nihilista. Afirmaciones a las que Heidegger salió al paso en la Carta sobre el humanismo (1947), en el epílogo (1943) y en el prólogo a Was ist Metaphysik? (1949).
} 
En su estudio Nietzschez Wort “Gott ist tot”, Heidegger comienza por denunciar la confusión, pues no basta con profesar una metafísica, ni siquiera la fe cristiana, para considerarse fuera del nihilismo. Como, a la inversa, el hecho de que alguien intente esclarecer la nada y su esencia no autoriza a calificarlo de nihilista.

El nihilismo de que se ocupa Nietzsche no es una doctrina sino un movimiento histórico, un acontecimiento decisivo en la historia de los pueblos occidentales; es el movimiento fundamental de la historia de Occidente. "Tiene tal profundidad, que su despliegue puede todavía desencadenar catástrofes”, decía Heidegger hacia 1940. El término se generalizó en la pasada centuria, pero no es un producto suyo ni de aquellas naciones cuyos pensadores hablan de nihilismo. Tal vez los que se imaginan libres de él son los más sometidos a su dominio. "Pertenece, [dice Heidegger] a la esencia de este extrañísimo huésped el no poder conocer su propio origen”. Lo más frecuente es considerar el nihilismo como una secuela de la descristianización occidental, del libre pensamiento o del ateísmo, pero ya advertía Nietzsche, en el pasaje del hombre loco, que la frase de Dios ha muerto nada tenía que ver con el ateísmo. Para Heidegger, particularmente, el Dios que ha muerto no es, pensado esencialmente, sino el mundo ideal suprasensible procedente de Platón, que ha sido norma para Occidente.

La metafísica sería el suelo y ámbito donde tiene lugar el acontecimiento llamado nihilismo, metafísica entendida como concepción general del ente bajo el esquema platónico del mundo sensible y suprasensible, el primero regido por el segundo. La desintegración de lo suprasensible en sus múltiples formas: ideas, Dios (el de la metafísica), ley moral, autoridad de la razón, el progreso, la felicidad de los más, la cultura, la civilización, en fin, todo concebido como un acontecimiento metafísico.

Por ignorar este enraizamiento metafísico, y por lo mismo su remoto origen y larga pervivencia, se cae en la ingenuidad de combatir aquellos fenómenos que no son más que derivaciones del nihilismo, confundiéndolos con éste o con sus causas; así, la prepotencia de la técnica como culpable de la situación espiritual de nuestro tiempo. Nietzsche, para el pensador de la Selva Negra, ha sido el primero que ha tomado conciencia del nihilismo y ha intentado pensarlo. Pero, ¿ha comprendido su esencia? En una nota de 1887 recogida en Der Wille Zur Macht se preguntaba el filósofo de Turín: ¿qué significa nihilismo? Y respondía: que los más altos valores se desvalorizan. Nietzsche aquí subraya esas palabras y añade otra aclaración: "Falta el fin; falta la respuesta al por qué”. En la era del nihilismo los valores supremos (Dios, ideas o ideales, fines y fundamentos, lo verdadero, lo bueno, lo justo y lo bello), todo aquello que regía y determinaba la vida humana ha 
perdido vigencia. Y la ha perdido porque ha surgido la sospecha de que el mundo ideal no puede plasmarse en el real. La obligatoriedad de los más altos valores se hace problemática. Comúnmente se interpreta la desvalorización de los supremos valores como una decadencia, pero para Nietzsche se trata de algo más hondo: una ley histórica, la lógica interna de la historia occidental.

Cuando el Dios metafísico es desalojado de su lugar, de su mundo, éste vacío queda en disponibilidad, como invitando a que sea ocupado por otros valores. Esta invitación, que es tentación, ha sido consentida, según Nietzsche; el lugar vacío ha sido ocupado por nuevos ideales: la felicidad terrena, el socialismo, la música de Wagner, etcétera. Lejos de superarse, el nihilismo, queda agudizado; es lo que Nietzsche llama nihilismo imperfecto. De él dice el mismo Nietzsche: "el nihilismo imperfecto: sus formas: vivimos en medio de ellas. Los ensayos de escapar al nihilismo sin derrocar los valores tradicionales: producen el efecto contrario, agudizan el problema”. En su acercamiento al pensamiento nietzscheano, Heidegger se explica así: los lugares vacíos que conserva el nihilismo imperfecto no son sino el reino ideal de lo suprasensible; el nihilismo perfecto debe eliminar el lugar mismo, lo suprasensible como región y reino, para colocar los nuevos valores en otro lugar y así instaurar un nuevo principio de valores y superar de verdad el nihilismo. Hay que sustituir el mundo de lo suprasensible, ya exangüe, por algo que sea más vivo; el nihilismo perfecto, clásico — de ambos modos los denomina Nietzsche—buscará un ideal que sea el ideal más exuberante.

Nietzsche había interpretado la esencia del nihilismo desde la perspectiva del valor, y no sin razón, observa Heidegger que la aclaración de lo que Nietzsche piensa bajo la etiqueta de valor es la clave para entender su metafísica. Que la palabra valor sea esencial en la doctrina de la voluntad de poder lo deja entender Nietzsche en el subtítulo de la obra que había de contener esa doctrina: "Ensayo de una transmutación de todos los valores”. En una nota de 1887-1888, recogida en Der Wille zur Macht, Nietzsche había propuesto la siguiente definición de valor: "el punto de vista del valor es el punto de vista de las condiciones de conservación y crecimiento respecto de estructuras complejas — de duración relativa- de la vida dentro del devenir”. ${ }^{3}$ Como punto de vista que es, el valor está determinado por y para un ver, un ver que es representar y, como tal, implica como ingrediente esencial la tendencia o apetito, como había señalado Leibniz (el appetitus,

3 “Der Gesichtpunkt des "Wertes” ist der Gesichspunkt von Erhaltungs-, Steigerungs-Bedingungen in Hinsicht auf complexe Gebilde von relativer Dauer des Lebens innerhalb des Werdens”. 
concomitante de la perceptio). El valor es punto de vista y punto de vista es el hecho de ser todo ente representativo-apetitivo. Es decir, valor significa para Nietzsche tanto como condición de la vida, algo que se requiere para que la vida sea vida. Vida en Nietzsche es lo mismo que ente; vida es cada ente y el conjunto de los entes. En este sentido, los valores son condiciones de conservación y crecimiento de la vida. De estas dos notas la decisiva es la segunda: la superación (Steigerung über sich hinaus). De aquí que el valor como condición de la vida tenga que concebirse como aquello que excita y fomenta el incremento de la vida; sólo lo que eleva la vida tiene valor o, más exactamente, es un valor. ${ }^{4}$ Las condiciones que apuntan a la mera conservación se convierten en impedimentos para la elevación de la vida y son, estrictamente hablando, desvalores, que es lo que eran los supremos valores tradicionales. Esto es lo que para Nietzsche exige, demanda una "transmutación de todos los valores anteriores y una nueva posición de valores”. ${ }^{5}$ La vida transcurre dentro del ámbito del devenir (werden), pero el devenir para Nietzsche es en el fondo lo mismo que voluntad de poder, "Voluntad de poder, devenir, vida y ser en el más amplio sentido significan en el lenguaje de Nietzsche lo mismo”, dice Heidegger. En el seno del devenir se configura la vida, lo viviente, en los respectivos centros y estructuras de poder: arte, Estado, religión, ciencia, sociedad. La voluntad de poder es, pues, la que determina todos los puntos de vista, todos los centros de dominio y, por tanto, todos los valores; la voluntad de poder es el origen, a la vez, de la necesidad y de la posibilidad de la posición de valores; es ella la que los necesita y los hace posibles. De ahí las palabras de Nietzsche: "Los valores y su mutación están en relación con el incremento del poder del que pone los valores”. ${ }^{6}$

DE LA VOLUNTAD DE PODER

\begin{abstract}
Al pensamiento nietzscheano de la voluntad de poder lo denominamos su pensamiento único. Con ello queda dicho al mismo tiempo que el otro pensamiento de Nietzsche, el del eterno retorno de lo mismo, está necesariamente incluido en el de voluntad de poder. ${ }^{7}$
\end{abstract}

\footnotetext{
${ }^{4}$ Martin Heidegger, Nietzsche I, traducción de Juan Luis Vermal, Barcelona, Destino, 2000, p. 394. En lo sucesivo sólo citaré $N$. I o N. II, según sea alguno de los dos tomos.

${ }^{5} N$. I, véase el capítulo 3.

${ }^{6}$ Cfr. Martin Heidegger, Holzwege, 3, Frankfurt am Main, Unveränd, Aufl., 1957, pp. 201-213.

${ }^{7}$ N. I, p. 389.
} 
El título voluntad de poder es un término fundamental de la filosofía definitiva de Nietzsche, de su metafísica, que es metafísica de la voluntad de poder. Nietzsche habla por primera vez de la voluntad de poder en un contexto revelador: en la segunda parte de Also sprach Zarathustra, que apareció en 1883, un año después de Die fröhliche Wissenchaft dice el filósofo: "Allí donde encontré algo vivo, encontré voluntad de poder”. Querer es querer-ser-señor; también en la voluntad de servicio hay voluntad de poder, no sólo porque el servidor aspire a dejar su condición para convertirse en señor; también ser-servidor es querer-ser-señor. Querer, explica Heidegger, no es un desear, simple aspiración, propensión a algo, sino que incluye en sí mandar. Quien manda es señor en cuanto dispone con su saber sobre las posibilidades de obrar; en el mandato se manda la realización de lo dispuesto y planeado. En el mandato obedece el que manda, no sólo el que ejecuta; obedece a ese disponer y poder disponer, y así se obedece a sí mismo; mandar es superarse (obedecerse) a sí mismo y es más fácil que obedecer; sólo a quien no es capaz de obedecerse a sí mismo hay que mandarle. De igual forma el poder de la voluntad de poder no es sino el modo como la voluntad se quiere a sí misma: un mandato, un mandar; al mandar, la voluntad es una misma cosa con lo mandado, con lo querido.

La esencia de la voluntad de poder es la misma esencia del querer: querer es voluntad de poder. El querer es la nota fundamental de todo lo real, la esencia más íntima del ser, dice Nietzsche (donde ser = el ente en su totalidad). No se trata pues de psicología, sino de metafísica; aquí la realidad, el ente, sigue concibiéndose como en toda la tradición metafísica como hypokeímenon, es decir, sub-jectum. Sólo que ya con Leibniz el êidos (forma del ente) se había transformado en perceptio, acompañada del appetitus. En Nietzsche, el appetitus de la perceptio se metamorfosea en voluntad de poder. La ousía o entidad del ente, el sub-jectum se había transmutado en la Edad Moderna en subjetividad de la conciencia, pero esta subjetividad es ahora, con Nietzsche, cuando muestra su verdadero rostro, lo que en el fondo era: voluntad de querer, el querer del querer. "Querer [dice Nietzsche] es tanto como querer llegar a ser más fuerte, querer crecer, y además querer los medios”. Los medios esenciales son las condiciones que pone la voluntad de poder y que Nietzsche los llama valores. "En todo querer hay un estimar”, decía Nietzsche, pero estimar significa aquí poner la condición de la conservación y aumento de poder; la voluntad de poder es esencialmente voluntad que pone valores, los cuales son las condiciones de conservación y 
acrecentamiento del poder dentro del ser del ente. La voluntad de poder se revela en su verdadera realidad como el fundamento y ámbito de la posición de valores.

La voluntad de poder y la posición de valores son la lógica consecuencia, la consumación de la metafísica, ante todo de la moderna. Esta última se afana tras lo incondicionalmente indubitable, lo cierto, la certeza, firmum et mansurum quid stabilire, en expresión de Descartes. Lo permanente, lo constantemente presente es desde antiguo el hypokeímenon, el sub-jectum, lo que subyace, y modernamente la verdad como certeza, el ego cogito, la subjetividad de la conciencia como certeza.

Nietzsche, según Heidegger, desarrolla la lógica interna de esta concepción. La verdad y la certeza ${ }^{8}$ son en su última esencia valores y valores puestos por la voluntad de poder, es ella quien debe poner las condiciones de mantenimiento y conservación de sí misma, por tanto, de la aseguración de sí misma y del ente. El ente, que está presente en la representación, no queda asegurado sino por la seguridad de tenerlo por verdadero, es decir, por la certeza; luego el fundamento último de la verdad y de la certeza es la voluntad de poder; verdad y certeza son valores exigidos y puestos por la voluntad de poder. La doctrina de Nietzsche sobre la voluntad de poder como esencia de toda realidad es la culminación de la metafísica moderna de la subjetividad. Por eso puede escribir el maestro de Basilea: “el problema de los valores es más fundamental que el problema de la certeza; este último sólo alcanza sentido bajo el presupuesto de que el problema del valor ha sido solucionado".

¿Qué metamorfosis ha sufrido la noción de verdad? Ya no es como para los primeros pensadores: patentización del ente, ni como para los medievales la adecuación del conocimiento con el objeto, ni la certeza como una posición de seguridad, no, verdad es ahora la “estable aseguración del ámbito desde el que la voluntad de poder se quiere a sí misma”. Pero esta idea nietzscheana de verdad es el precipitado de todo el proceso histórico en que quedan incluidos los momentos anteriores. La verdad es un valor necesario para la autoaseguración de la voluntad de poder, pero no es el más alto valor. La verdad es necesaria para mantenerse la voluntad en el poder alcanzado, pero es impotente para hacerle escalar nuevos grados de poder: la verdad no abre posibilidades a la voluntad.

La liberación de la voluntad hacia sus posibilidades es una función del arte. Pero Nietzsche no concibe el arte como un artista. En Der Wille zur Macht hace

${ }^{8}$ La certeza no es sino la seguridad de tener algo por verdadero. 
la anotación siguiente: "La obra de arte, cuando aparece sin artistas, por ejemplo, como cuerpo, como organización. [..] Hasta qué punto es el artista sólo una etapa previa. El mundo como obra de arte que se alumbra a sí misma”. La esencia del arte, vista desde la voluntad de poder, consiste en ser algo que excita y aguijonea al querer; Nietzsche lo expresa diciendo que el arte es "el gran estímulo de la vida". ${ }^{9}$ Por ello, pudo decir Nietzsche que "el arte es más valioso que la verdad". He aquí el principio fundamental de la voluntad de poder.

La experiencia de la desvalorización de todos los valores tradicionales (entendidos éstos como el mundo suprasensible platónico) culmina en la conciencia de que Dios ha muerto, de que los fines, metas e ideales de la precedente metafísica se han hecho ineficaces, han quedado inertes. Pero la desvalorización incluye para Nietzsche un aspecto positivo; como señala el Loco de Die fröhliche Wissenschaft, el hombre camina a una más alta historia desde el momento que la voluntad de poder se establece como principio de todo valor — la voluntad que es la realidad de lo real, el ser del ente. Es lo que quiere expresar la frase con que Nietzsche da conclusión a la primera parte de Also sprach Zarathustra: "Todos los dioses han muerto, ¡viva el superhombre!”.

\section{El SUPERHOMBRE DE NietZSCHE EN HEIDEGGER}

El superhombre para Heidegger es una noción metafísica, hija de la lógica interna de la metafísica occidental, que está determinada por la voluntad de poder. Si la realidad es voluntad de poder, hay que decir que el hombre está destinado y predestinado a la dominación de la Tierra, cumpliendo así hasta el extremo el mandato del Antiguo Testamento. Pero ¿̇hasta qué punto está el hombre actual capacitado para llevar a cabo la dominación sobre todo ente? No hay duda que el hombre tiene que trascenderse a sí mismo, superando lo que ha sido hasta ahora, la superación del hombre anterior es el superhombre.

Nietzsche encarna su doctrina del superhombre en la figura legendaria de Zaratustra. Pero ¿quién es el Zaratustra? "Zaratustra es sólo el maestro, no ya el

\footnotetext{
${ }^{9}$ De acuerdo con los primeros pensadores griegos (zoé, physis), Nietzsche escribe con frecuencia vida como sinónimo de voluntad de poder en cuanto realidad de lo real. Así, el arte sería la condición para que la voluntad se eleve al poder y lo acreciente. El arte es, por lo mismo, un valor. En la jerarquía de los valores es el valor supremo, por ser aquello que posibilita toda elevación de poder, un valor superior a la verdad.
} 
superhombre mismo. Y Nietzsche no es Zaratustra, sino el interrogador, el que intenta medir la esencia de Zaratustra”. ¿Quién es esa figura enigmática que reaparece en la época de la consumación de la metafísica? Para Heidegger sigue siendo todavía eso, enigma que apenas hemos comenzado a descifrar, entre otras razones porque Zaratustra es el maestro ambiguo que enseña a la vez el superhombre y el eterno retorno. “¿Quién es el Zaratustra de Nietzsche? Es el portavoz de Dionisos. Esto significa que Zaratustra es el maestro que en su doctrina del superhombre y para esta doctrina enseña el eterno retorno de lo igual”. ${ }^{10}$

En el diálogo que entablaron, por encima de la doble celebración de su sexagésimo cumpleaños, Ernst Jünger y Martin Heidegger, diálogo que tomó la forma de un tratado sobre el nihilismo, el primero posibilitó pensar con el título mismo, “Más allá de la línea”, que cumplía el cruce de la zona crítica, o que podría cumplirse. Pero el segundo, con más rigor, dando otro sentido al mismo título, anotaba en seguida que el movimiento del nihilismo consiste en dejar indeciso, cuando se acaba, lo que significa este acabamiento: o su fin o su cumplimiento - y lo que significa este cumplimiento: el paso a la nulidad de la nada o a la región de un nuevo giro del ser- - Asimismo, observaba que es muy peligroso describir la acción del nihilismo, porque la descripción ya forma parte de la acción; sin embargo, si pretender dar una buena definición del nihilismo es una pretensión rara, renunciar a esta tentativa es dejar el campo libre a lo que tal vez es esencial en él: su don de disfrazamiento, su negativa a confesar sus orígenes, su poder de sustraerse a toda explicación decisiva. Hablamos del paso de la zona crítica, pero el hombre no es sólo un transeúnte, que únicamente tendría una relación geográfica con lo que cruza, no sólo está en la zona, él mismo es, aunque no por sí solo ni para sí solo, esta zona y esta línea. Heidegger sugería que estaríamos bien inspirados escribiendo en adelante la palabra ser y la palabra nada solamente tachadas por una cruz de san Andrés: ser, nada.

En la respuesta que Heidegger le da a Jünger a su texto Sobre la línea, Heidegger enuncia de manera enigmática el hecho de que:

Hablar de la subjetidad (no subjetividad) de la esencia humana como el fundamento de la objetividad de todo subiectum (de todo presente) parece en todos aspectos paradójico y artificial. Esta apariencia tiene su fundamento en que apenas hemos comenzado a preguntar

${ }^{10}$ Ibid., pp. 123-124. 
por qué y de qué manera será necesario dentro de la metafísica moderna un pensar que Zaratustra representa como forma. ${ }^{11}$

En un borrador de Also sprach Zarathustra escribe Nietzsche: "Hemos creado el pensamiento más difícil, creemos ahora el ser para el cual sea leve y dichoso". Ese pensamiento es el pensamiento del eterno retorno de lo mismo, el más grave y difícil, según glosa Heidegger, ${ }^{12}$ en un doble sentido correspondiente al término alemán schwer: el más difícil y el más grave, el de más peso, el más oneroso. $\mathrm{El}$ eterno retorno de lo mismo significa la voluntad de poder afrontada desde el ángulo de la existencia. Esto es, que constituye la determinación del ente en su totalidad. Desde este punto de vista, el eterno retorno no puede ser considerado como un simple accesorio mítico del pensamiento nietzscheano, sino que se inscribe de modo riguroso en la economía del sistema. En la carta sobre el humanismo escribe Heidegger, a propósito de la existencia: "Kant la piensa como realidad en el sentido de objetividad de la experiencia; Hegel la determina como idea de la subjetividad absoluta que se sabe a sí misma. Nietzsche la concibe como eterno retorno de lo mismo". ${ }^{13}$

En su obra sobre Nietzsche se explicita este pensamiento: el ente fundamentalmente caracterizado, en cuanto tal, como voluntad de poder no podría ser otra cosa en su totalidad que eterno retorno de lo mismo. $Y$ a la inversa: el ente que en su totalidad es eterno retorno de lo mismo debe necesariamente tener, en cuanto ente, el carácter fundamental de la voluntad de poder. La propiedad del ser del ente y la integridad del ente exigen de manera recíproca, y a partir de la unidad de la verdad del ente, el modo de su esencia respectiva. ${ }^{14}$ ¿En qué consiste lo propio del eterno retorno? El eterno retorno es la voluntad de poder en cuanto que, a través de su incesante superación de todo poder dado, "retorna al interior de sí misma". ${ }^{15}$ "El eterno retorno es la manera como lo inconsistente (el devenir) se presencializa en cuanto tal, y esto dentro de la suprema consistencia (el movimiento cíclico), con el único objeto de afirmar la constante posibilidad del ejercicio del poder”. ${ }^{16}$

\footnotetext{
${ }^{11}$ Ernst Jünger y Martin Heidegger, Acerca del nihilismo, Barcelona, Paidós, 1994, p. 88.

${ }^{12}$ N. I, p. 417 (pp. 274 y 276 de la edición en alemán).

${ }^{13}$ Martin Heidegger, Über den Humanismus, Frankfurt am Main, 1947, p. 59. En lo sucesivo citaré UH.

${ }^{14} N$. I, p. 228 de la edición alemana.

${ }^{15}$ Ibid.

${ }^{16}$ Ibid., p. 230.
} 
Heidegger reconoce que Nietzsche padeció oscuridades y curiosos desvíos a la hora de explicar el hallazgo del eterno retorno, pero la oscuridad es, en parte, inherente al tema mismo, ante ella Nietzsche "tuvo que retroceder espantado". Se trata de un pensamiento oscuro. Este pensamiento, dice Heidegger, "está ya” en la metafísica occidental y no sólo este pensamiento aislado, sino "todo Nietzsche”, precisamente su meditación está encaminada a descubrir en él la raíz común con el pensar occidental; Heidegger no cree haber disminuido con ello un ápice la originalidad y la grandeza de Nietzsche, pero tampoco se cree excusado de pensar a fondo "el pensamiento más difícil [...], el más grave pensamiento". ${ }^{17}$

Pues cuando se revele a la luz del día, en un futuro más o menos lejano, la esencia de la técnica moderna, se caerá en la cuenta de la terrible realidad del eterno retorno. Lo cual equivale a decir que la técnica moderna no es sino su realización más perfecta, un intento de eterno retorno de lo mismo, fundado en una concepción de la realidad como si está fuera algo siempre idéntico y siempre reversible en un proceso interminable. ${ }^{18}$ No se trata de una convicción personal y menos aún de una convicción religiosa, sino del pensamiento de la esencia del tiempo. Lo que Nietzsche piensa a través del eterno retorno es, por tanto, "el ser en cuanto tiempo". ${ }^{19}$ Así pues, al interpretar la voluntad de poder como eterno retorno de lo mismo, Nietzsche - lo que ha puesto al descubierto - es otra nota constitutiva del ente que siempre había quedado en el trasfondo: el tiempo. Por eso opina Heidegger que la unidad de voluntad de poder y eterno retorno de lo mismo, el pensamiento más arduo, el pensamiento más difícil de Nietzsche, equivale a la unidad de ser y tiempo.

Sin embargo, a pesar de que Nietzsche no tuvo plena conciencia de esta equivalencia y, en general el filósofo de Basilea no se planteó el problema de ser y tiempo (aunque tampoco se plantearon este problema ni Platón ni Aristóteles, aunque tropezaron con él al concebir el ser desde una dimensión temporal, como ousía, presencia), este pensamiento (que podría haber sido la cima de la meditación de Nietzsche), se desarrolla aún dentro del marco de la metafísica. Es verdad que el ser ya no se concibe separado del devenir, pues como decía Nietzsche "Imprimir al devenir el carácter de ser: he aquí la suprema voluntad de poder”, ${ }^{20}$

\footnotetext{
${ }^{17}$ Ibid., p. 26.

${ }^{18}$ Martin Heidegger, Was heisst Denken, Tübingen, 1954, pp. 24-43, 63-78.

${ }^{19} N$. I, p. 26 de la edición en alemán.

${ }^{20}$ Citado en N. II, p. 231 de la edición alemana.
} 
Nietzsche, empero, no ha privilegiado al devenir más que dándole el carácter de presencia constante, pensándolo en su relación con la consistencia del ente metafísicamente concebido, es decir, con la voluntad de poder. De esta forma, el eterno retorno de lo mismo permanece todavía dentro de una concepción metafísica del tiempo:

\footnotetext{
Desde el principio de la metafísica occidental, el ser ha sido comprendido como consistencia de la presencia. Aquí la consistencia significa, de manera equívoca, tanto la fijeza como la perseverancia (o la consistencia). La noción nietzscheana del eterno retorno de lo mismo enuncia esta misma esencia del ser. Es cierto que Nietzsche concibe el ser como siendo lo consistente, lo fijo, lo solidificado y lo estático, oponiéndolo así al devenir. Y no obstante reside el ser en la voluntad de poder, la cual debe afirmarse en la consistencia a partir de algo consistente. Es verdad que esto ocurre así con el único fin de superarse de manera constante, esto es, de devenir. ${ }^{21}$
}

Para Nietzsche, el devenir, el movimiento del mundo finito, transcurre en un tiempo que es efectivo e ilimitado. En este tiempo infinito, el movimiento del mundo tiene que refluir en sí, dado que no alcanza ningún estado de equilibrio. El devenir que refluye en sí es el eterno retorno. Tal retorno podría solamente ser evitado si hubiera sido excluido por una intención y una finalidad anticipantes. Sin embargo, Nietzsche excluye una tal intención y una tal finalidad en cuanto piensa el mundo como caos, rechazando así de antemano toda voluntad creadora y ordenadora. ${ }^{22}$ De hecho, el pensamiento del eterno retorno es tan poco calculado y dispuesto que tuvo que venir a él y ello en un lugar y en un tiempo bien determinado: en agosto de 1881, a seis mil pies de altura, ante un monumental bloque de piedra en forma de pirámide, en la Engadina. Un pensamiento que llegó como llegan todos los grandes pensamientos: inopinadamente porque estaba preparado y penosamente elaborado por un largo trabajo. Tal pensamiento exigía un viraje decisivo de un pensar que no podía hablar sobre su pensamiento decisivo porque era justamente ese viraje el que debía ser la sede de su despliegue. ${ }^{23}$

Si es cierto que el auténtico pensamiento del tiempo resulta ser el criterio fundamental para un acertado planteamiento de la cuestión del ser, hay que decir

\footnotetext{
${ }^{21}$ Ibid.

${ }^{22}$ Ibid., pp. 341 y ss.

${ }^{23}$ Ibid., p. 263.
} 
que Nietzsche se limita a presentir tan sólo este pensamiento. La concepción del eterno retorno de lo mismo le separa de aquel pensamiento y le proyecta hacia la metafísica, y así la presencia del ser se confunde con el tiempo presente del ahora. Heidegger descubre esta confusión de manera particularmente clara en el análisis de la significación del instante en el eterno retorno nietzscheano. ${ }^{24}$ El retorno y lo eterno requieren un pensar a partir del instante. El devenir se condensa en la eternidad del instante; en rigor, la eternidad y para el caso el tiempo del eterno retorno de lo mismo no pueden comprenderse más que en y por el instante, decía Nietzsche.

El instante, que es donde la eternidad alcanza validez, no es representable como punto temporal, a esto se debe que tampoco el retorno pueda ser medido cronológicamente: entre uno y otro retorno no se da ningún tiempo, “pasa rápido como un rayo, y ello aunque criaturas vivientes lo midieran por billones de años o ni siquiera pudieran llegar a medirlo”. ${ }^{25}$ El instante es la decisión de la que todo depende.

Pero el instante es una noción ambigua que puede significar tanto la fijación puntual de la presencia como la unidad de los éxtasis temporales, cuya comprensión podría conducir a una concepción no metafísica del hombre:

Por el instante determinamos el tiempo en que futuro y pasado se contraponen en el momento mismo en el que son sobrepasados y consumados por el hombre. Esto es así por el hecho de situarse el hombre mismo en el lugar de esta colisión; más todavía, por ser el hombre mismo este lugar. ${ }^{26}$

Nietzsche, en realidad, no alcanza esta comprensión. Lo que hay en el fondo es aquello que Klossowsky sentencia:

El eterno retorno, necesidad que hay de querer: sólo el que soy ahora puede anhelar esa necesidad de mi retorno y de todos los acontecimientos que desembocaron en lo que soy - por eso aquí la voluntad supone un sujeto; ahora bien, ese sujeto no puede ya querer ser el mismo que el que fue hasta ahora, pero quiere que estén dadas todas las condiciones para eso; ya que, abarcando con una sola mirada la necesidad del eterno retorno como ley universal, desactualizo mi yo actual para pretenderme en todos los otros yoes cuya serie

${ }^{24}$ Ibid., p. 279.

${ }^{25}$ Ibid., p. 399.

${ }^{26}$ Ibid.

${ }^{27}$ Pierre Klossowsky, Nietzsche y el círculo vicioso, Altamira, La Plata, 1995, p. 65. 
debe ser recorrida con el fin de que, al seguir el movimiento circular, vuelva a ser lo que soy en el instante de descubrir la ley del eterno retorno. ${ }^{27}$

En el instante en que se me revela el eterno retorno dejo de ser yo mismo hic et nunc:

\begin{abstract}
¡Mira este portón! ¡Enano!, seguí diciendo: tiene dos caras. Dos caminos convergen aquí: nadie los ha recorrido aún hasta su final [...] Esa larga calle hacia atrás: dura una eternidad. Y esa larga calle hacia delante — es otra eternidad [...] Se contraponen esos caminos: chocan derechamente de cabeza: —y aquí, en este portón, es donde convergen [...] El nombre del portón está escrito arriba: 'Instante’ [...] Pero si alguien recorriese uno de ellos — cada vez y cada vez más lejos: ¿crees tú, enano, que esos caminos se contradicen eternamente?- [...] Todas las cosas derechas mienten, murmuró con desprecio el enano. Toda verdad es curva, el tiempo mismo es un círculo [...] Cada una de las cosas que pueden correr, ¿'no tendrá que haber recorrido ya alguna vez esa calle? Cada una de las cosas que pueden ocurrir, ¿no tendrá que haber ocurrido, haber sido hecha, haber transcurrido ya alguna vez? ${ }^{28}$
\end{abstract}

El tiempo del eterno retorno de lo mismo resulta ser una inmovilización del devenir. No es de otro modo tal y como lo comprende Klossowsky cuando señala "que en el mismo instante en que se me ha revelado la necesidad del movimiento Circular jse presenta en mi vida como si nunca hubiese tenido lugar!”. ${ }^{29}$ Quizá por ello, bien pudo decir Heidegger que el eterno retorno sólo puede ser pensado por aquel joven pastor por cuya garganta repta una negra serpiente —el sombrío siempre da igual, el carecer de meta del nihilismo- y que no puede desembarazarse de esa serpiente sino mordiendo su cabeza: La idea del retorno no existe sino como esa mordedura, como esa decisión sobre el acontecer histórico del nihilismo. ${ }^{30}$

Es en este sentido en que el superhombre asociado y apropiado por el eterno retorno perdura todavía la imagen del hombre según la metafísica. Nietzsche, al proponer como único modo de superación del hombre actual, como puente hacia el superhombre, la redención de la venganza, lo que pide es la reconciliación con el tiempo, o, lo que es lo mismo, exhorta a una conversión en el seno de la voluntad misma; efectivamente, la realidad es concebida en la metafísica occidental como

\footnotetext{
${ }^{28}$ Friedrich Nietzsche, Así habló Zaratustra, Madrid, Alianza Editorial, 1981, pp. 226 y ss.

${ }^{29}$ Ibid., p. 66

${ }^{30}$ N. I, p. 445 de la edición en alemán.
} 
voluntad, como en aquellas frases de Schelling que decía que "querer es el ser primigenio", y precisamente uno de los predicados del ser en su plenitud ha sido desde siempre la "eternidad e independencia del tiempo". Pero hay que precisar.

Lo que propiamente repugna a la voluntad no es el pasar, sino la petrificación del pasar en el pasado irreversible e irremediablemente, la congelación de lo pasado en la rigidez de lo definitivo. ¿En qué puede consistir la redención de la venganza? No en escapar de los dominios de la voluntad, pues ésta sería la condenación a la nada, la aniquilación de la realidad, ya que el ser es, en la concepción de Nietzsche y de la metafísica tradicional, voluntad; la redención de la venganza consiste en la liberación de aquello que contraría y repugna a la voluntad: el fue, el pasado como tal, con lo cual la voluntad llegaría a la plenitud de sí misma.

No se trata de la liquidación del tiempo como pasar y transcurrir, la contrariedad de la voluntad cesa cuando el fue no queda solidificado en el pasado sino que retorna una y otra vez, convirtiéndose en un ir y venir, pasar y volver de las cosas. A esto nada tiene que oponer la voluntad, nada tiene que objetar al constante retorno de todo, y si ese retorno de lo mismo es eterno, satisface toda la necesidad de la voluntad, uno de cuyos atributos es la tendencia a la eternidad: la voluntad sólo lo es pleno queriendo eternamente y siendo eterno aquello que quiere.

En resumen, podría decir que la idea de Heidegger es que las dos teorías fundamentales de Nietzsche, la voluntad de poder y el eterno retorno de lo mismo, dicen en el fondo lo mismo; ambas piensan lo esencial de la metafísica occidental, la primera en el lenguaje de la metafísica moderna y la segunda en el de su consumación o culminación. Basta, para convencerse de ello, con reconstruir el esquema fundamental de la metafísica: ésta se propone conocer en ente en su entidad, es decir, en cuanto ente, y cree haberlo logrado cuando ha establecido como notas fundamentales del ente la permanencia y la presencia; el ente sería lo permanente y presente, la presencia permanente; la voluntad de poder sería la consistencia de la realidad y el eterno retorno su modo de existir. Pero algo de esto entrevió Nietzsche: ““El eterno retorno de lo mismo’ es el nombre del ser del ente. 'Superhombre' es el nombre de la esencia del hombre que corresponde a este ser". ${ }^{31}$

El eterno retorno es, en efecto, un conato de superación de la noción tradicional de tiempo: la unidad de voluntad de poder y el eterno retorno quiere ser fusión no sólo del mundo sensible y suprasensible, de esencia y existencia, de ser y devenir, sino también de los tres momentos del tiempo en el ahora. Baste recordar aquí el

${ }^{31}$ Martin Heidegger, Vorträge und Ausätze, 2, Pfullingen, Unveränd. Aufl., 1959, p. 108. 
pasaje de Also sprach Zarathustra titulado "Del gran anhelo”, donde Zaratustra expone su doctrina del eterno retorno, que califica de su "pensamiento más profundo" en el diálogo con su propia alma: “Oh alma mía, yo te he enseñado a decir 'hoy' como se dice 'alguna vez' y ‘en otro tiempo' y a bailar tu ronda por encima de todo aquí y ahí y allá”. ${ }^{32}$

Con estas palabras, Nietzsche alude a la superación del tiempo. Lo que Zaratustra tiene que decir a su propia alma es que el futuro y el pasado son como el presente, pero que el presente a su vez es como el pasado y el futuro: todo es lo mismo, todo es igual; todo es una única actualidad, un constante ahora, el tiempo se convierte en una eternidad, sólo que para Nietzsche lo constante o lo igual no consiste en quietud, en un ahora congelado, sino en un retorno de lo igual, o, como dijera Klossowsky: el círculo vicioso. ${ }^{33}$ En el eterno retorno se afirma el ser del ente como devenir, en su eterno retornar; ya que si lo único subsistente es la infinitud del tiempo mismo, ningún fin como tal podrá ser alcanzado jamás.

Apenas alcanzada la cuota perseguida, esto es, el máximo de sentido, ese estado de equilibrio es roto para volver a recomenzar y garantizar así la eternidad del devenir.

\footnotetext{
Si el mundo tuviese un fin, este fin se habría ya logrado. Si hubiera algún estado final no previsto, también debería de haberse realizado. Si el mundo fuese, en general, capaz de persistir y de cristalizar de "ser"; si en todo su devenir tuviese sólo por un momento esta capacidad de "ser", hace mucho tiempo que hubiera terminado todo devenir, y por consiguiente, todo pensamiento, todo "espíritu”. El hecho de que el espíritu sea devenir demuestra que el mundo carece de meta, de estado final, y que es incapaz de ser. ${ }^{34}$
}

O como señala más adelante:

\footnotetext{
${ }^{32}$ Friedrich Nietzsche, Así habló Zaratustra, op. cit., p. 305.

${ }^{33}$ Cfr., Pierre Klossowsky, Nietzsche y el círculo vicioso, op. cit., pp. 73 y ss. Aquí, Klossowsky muestra la indisoluble unidad de la teoría de la voluntad de poder. Ésta, en tanto que voluntad de sobrepasarse, implica la incesante transfiguración de nuestro propio ser. En la transfiguración dejo de ser el que soy para pasar a ser otro, y sólo así soy el que verdaderamente soy, pues mi propia esencia consiste en la constante disolución de mi ser, como ser acabado. La transfiguración abre así a la incesante metamorfosis, donde toda identidad se disuelve en una múltiple alteridad. El círculo del eterno retorno implica necesariamente la realización sucesiva de todas las identidades posibles. Afirmar un solo instante de mi existencia actual, supone decir un sí a todos los instantes que lo han hecho posible y en, consecuencia, a la infinita serie de mis otras posibles identidades que ahora desconozco.

${ }^{34}$ Friedrich Nietzsche, La voluntad de poderío, Madrid, EDAF, p. 551.
} 
En un tiempo infinito, toda posible combinación debe ser también realizada una vez; aún más, debe ser realizada infinito número de veces. [...] El mundo es un círculo que ya se ha repetido una infinidad de veces y que seguirá repitiendo in infinitum su juego. ${ }^{35}$

El principio de Nietzsche "imprimir al devenir el carácter del ser [...] ésta es la suprema voluntad de poder”, está postulando una reforma paralela del tiempo en el sentido del eterno retorno. Esto significa configurar el devenir, transmutarlo en ente, de tal modo que subsista como devenir y a la vez goce de permanencia, es decir, sea. ¿En qué puede consistir tal transmutación? En conducir el devenir a sus más altas expresiones, en sus más altas posibilidades, las cuales, una vez alcanzadas, vendrán a ser como el ámbito y medida en que el devenir logre estabilidad y permanencia: La mágica transmutación se obtiene por el obrar creador, por el crear, una operación en la que se unifican pasado y presente con vistas al futuro, quedando todo reunido en la momentaneidad o instantaneidad.

El retorno es para Zaratustra "la inagotable plenitud del gozoso y doloroso vivir”, su gran anhelo. Nietzsche se refiere también a la nostalgia como la nostalgia de la superplenitud, de la que extrae su único consuelo y su mayor esperanza. ¿De qué y por qué?, se pregunta Heidegger. Contesta Zaratustra: “Que el hombre se redima de la venganza: eso es para mí el puente hacia la suprema esperanza y un arco iris tras larga tempestad”.

La filosofía se estremece en Nietzsche. ¿Pero esto ocurre sólo porque sería el último de los filósofos (cada filósofo es siempre el último)? ¿O más bien porque lo llama un lenguaje totalmente otro, la escritura de fractura, cuya vocación sería la de suponer las palabras tachadas, espaciadas, puestas en cruz, dentro del movimiento que las aparta, pero también las retiene en este apartamiento como lugar de la diferencia, debiendo así confrontar una exigencia de ruptura que lo desvía constantemente de todo lo que tiene poder de pensar? ¿Cuál sería entonces esta exigencia si suponemos que nosotros mismos, a quienes detiene, podemos designarla sin interrumpirla, ni ser interrumpidos por ella? ${ }^{36}$

\footnotetext{
${ }^{35}$ Ibid., p. 553.

${ }^{36}$ En este punto es conveniente remitirse a un espléndido ensayo de Maurice Blanchot sobre Nietzsche, El diálogo inconcluso, especialmente, "Nietzsche y la escritura fragmentaria", Caracas, Monte Ávila Editores, p. 252 y ss.
} 
De modo particular, cuando el pensador de Holzwege expone que en el superhombre es todavía el hombre lo pensado, no es necesario entender esta afirmación crítica en el sentido de que Nietzsche hubiese únicamente formulado mal lo que quería decir. Nietzsche aspiró a superar el nihilismo con un nuevo principio de valores, la voluntad, pero permanece ligado a una metafísica de valores: Heidegger se pregunta si el verdadero nihilismo no será el pensar en términos de valor. La metafísica de la voluntad de poder pretendía ser la superación del nihilismo, y lo es, si se concibe el nihilismo como desvalorización de los valores precedentes y a la voluntad de poder como un nuevo principio de valoración; no lo es, en cambio, si por nihilismo se entiende la ausencia del ser. El pensar axiológico es el mayor enemigo del ser, porque el valor no le deja ser al ser, dice Heidegger, por ello, la pretendida superación del nihilismo no es sino su consumación. El pensar valorativo que queda entronizado como principio supremo en la voluntad de poder, no sólo vacía al ente de su ser-en-sí, sino que provoca el vacío del ser mismo, que sólo tiene entrada bajo la figura del valor, pero el degradar al ser en valor es la radical muerte violenta.

La metafísica de la voluntad de poder es mortal en el sentido más extremo: en cuanto impide al ser entrar en lo vivo de su esencia, en su verdad. La muerte del ser no es una exclusividad de la voluntad de poder; no es sólo la concepción de la realidad como voluntad de poder la que no le deja vivir al ser y si así fuera, la metafísica anterior a Nietzsche habría tenido alguna experiencia y pensado el ser en su verdad o al menos se lo habría planteado como problema, pero en ninguna parte encontramos tal experiencia del ser mismo, y menos aún se ha pensado el ser o la verdad como ser, ni siquiera en la filosofía presocrática, aurora del pensar occidental. La famosa frase de Parménides "el ser es" nombra el ser mismo, pero no lo piensa, no lo hace presente desde su verdad o patentización. La historia del ser comienza con el olvido del ser, el cual Heidegger califica de extraño y a la vez necesario y que no es una especialidad de la metafísica de la voluntad de poder, sino de la metafísica como tal.

La metafísica en cuanto metafísica es el auténtico nihilismo. La metafísica de Platón no es menos nihilista que la metafísica de Nietzsche. En aquel queda oculto el nihilismo, en éste se hace patente, dice Heidegger. En semejante ecuación de metafísica y nihilismo no se sabe qué admirar más, si la arbitrariedad o la ignorancia de la historia entera. 
Ahora bien, la metafísica de Nietzsche, por estar vinculada a la representación, es esencialmente una filosofía de la subjetividad, puede decirse incluso que es la forma consumada de la filosofía del sujeto, destino de los tiempos modernos. Para comprender esto hay que clarificar que ha sido Descartes quien, con el cogito ergo sum, ha dado forma a la filosofía del sujeto en los tiempos modernos. Nietzsche ha sido, en contraposición, el pensador que ha rechazado el cogito y su yo. ¿Cómo, entonces, puede sostenerse sin contradicción que Nietzsche es un filósofo del sujeto?

No pretendemos afirmar para justificar esta paradoja, que Nietzsche enseñó las mismas cosas que Descartes. Afirmamos algo mucho más esencial, a saber: que Nietzsche piensa lo mismo en el cumplimiento histórico de la esencia. ${ }^{37}$

La oposición explícita a Descartes y a todo lo que éste representa se desarrolla a partir de los mismos presupuestos y dentro del mismo campo del pensamiento cartesiano, en lo que concierne a la comprensión o, mejor, a la equivocada interpretación del problema del ser. Haciendo esto, Nietzsche lleva a su terminación algo que se encuentra en Descartes en estado germinal y bajo una forma casi irreconocible:

La postura de Nietzsche contra Descartes arraiga metafísicamente en el terreno mismo de la posición cartesiana. Sólo partiendo de esta posición puede Nietzsche tomar en serio, en un sentido absoluto, el cumplimiento de la esencia de esta posición. Es preciso, por tanto, que se someta a la experiencia de la fundamental posición de Descartes en cuanto relativa y todavía no cumplida, incluso en cuanto no posible. ${ }^{38}$

La interpretación heideggeriana, sobre este particular, tiene dos aspectos: la equivocada interpretación de Descartes por parte del pensador de Basilea y el carácter esencialmente subjetivo de la voluntad de poder y de todo lo que con ella se relaciona, en un sentido fundamentalmente cartesiano. Respecto del primer punto, imagina Nietzsche que lo propio del pensamiento cartesiano consiste en hacer surgir el pensamiento del yo. De aquí la célebre afirmación que hiciera Nietzsche en Más allá del bien y del mal, por encima del “viejo e ilustre yo” y también la afirmación: "Cierta cosa piensa”. ${ }^{39}$ Ahora bien, lo esencial del subjeti-

\footnotetext{
${ }^{37} N$. II, p. 121 de la edición alemana.

${ }^{38}$ Ibid.

${ }^{39}$ Friedrich Nietzsche, Par-delà bien et mal, p. 30 (Más allá del bien y del mal, traducción de Andrés Sánchez Pascual, Madrid, Alianza Editorial, 1972).
} 
vismo de Descartes, como lo apunta Heidegger, profundizando así una interpretación iniciada en Sein und Zeit, no reside de ninguna manera en la afirmación del yo. En cuanto posición metafísica fundamental el subjetivismo cartesiano se apoya sobre la concepción de la propiedad de ser del ente en general. Esta propiedad es la representatividad: el ente está establecido en lo representado. ${ }^{40}$

También la idea según la cual el pensar determina la posición del sujeto —y no a la inversa - se encuentra ya en Descartes. La perspectiva propuesta por Nietzsche no pasa de ser "una pretenciosa novedad". ${ }^{41}$ Siempre que el ser esencial del ente sea encerrado dentro del cerco de la representación, en cuyo interior lo subyacente esencial o subjectum viene o es llamado a ocupar un determinado lugar, la metafísica continuará moviéndose dentro del campo de la subjetidad. ${ }^{42}$ He aquí porqué

[...] la noción de sujeto no es otra cosa que la transformación de la noción de sustancia restringida al hombre en cuanto es éste el que se representa, en cuya representación la cosa representada y aquel que se la representa se encuentran fundados sólidamente en su interdependencia. ${ }^{43}$

En suma, la novedad de la posición de Nietzsche — en relación con Descartesconsiste en lo que aquél se limita a sobrevalorar en el hombre, concebido siempre según los principios de la metafísica cartesiana: el cuerpo en lugar del alma.

Gracias a este nuevo enclave, comprendido todavía en el interior del sujeto mismo, la voluntad de poder aparece y se ejerce: "El yo y no el cuerpo, es para Nietzsche lo 'subyacente’”. ${ }^{44}$ Pero el hecho de que Nietzsche introduzca el cuerpo en el lugar del alma y la conciencia, no cambia en absoluto la posición metafísica fundamental inaugurada por Descartes. Todo cuanto se refiere a la representación de la conciencia es transferible ahora al dominio del apetito, de las pulsiones, y aquí es concebido, de manera absoluta, desde un punto de vista de la fisiología de la voluntad de poder. Por tanto, por su aplicación al cuerpo, la voluntad de poder existe en cuanto simple

${ }^{40} N$. II, p. 146 de la edición en alemán.

${ }^{41}$ Ibid.

${ }^{42}$ Esta palabra la empieza a emplear Heidegger desde Holzwege, justo para evitar los equívocos de subjetividad, palabra que está excesivamente vinculada al yo, tanto filosófico como psicológico.

${ }^{43}$ N. II, p. 147.

${ }^{44}$ Ibid. , p. 150. 
subjetividad (subjetidad) humana, y sobre esta base lleva a cabo la humanización del ente en su totalidad. Nietzsche, en realidad, se encuentra desgarrado entre dos exigencias contradictorias: la deshumanización del ente y su radical humanización.

Esta última tendencia expresa en definitiva el sentido profundo de su metafísica. Un pasaje de la primera parte del estudio heideggeriano sobre Nietzsche expone esta esencial contradicción: la tendencia a desembarazarse de todas las humanizaciones existentes hasta entonces, y, de modo particular, de su aspecto suprasensible y moralizante, humanista y religioso, que constituye algo inherente al proyecto nietzscheano en la medida en que se proyecta hacia el ser, es decir, en la medida en que mira hacia el ente en su totalidad bajo el nombre de voluntad de poder. He aquí el sentido de su negativa a atribuir intención al todo, finalidad orgánica y, en una palabra, a subordinar el mundo a Dios. Pero ¿significa la deshumanización del ente, en un último análisis, algo más que des-divinización? El pensamiento de Nietzsche en torno a este punto permanece tenso entre la voluntad de naturalizar al hombre a partir de una des-divinización de la naturaleza y la voluntad de humanizar el mundo. ${ }^{45}$

Para Heidegger, la humanización actúa en el interior de la voluntad de poder, como pensamiento del cuerpo; como también el superhombre no es más que una repetición del hombre; como en el eterno retorno de lo mismo se limita a repetir el tiempo del hombre. A través de todos estos términos Nietzsche proyecta, sin duda, su intención más allá de una simple humanización; pero estos términos pretenden lo contrario de lo que expresan: "Nietzsche, en virtud de su voluntad de deshumanizar la interpretación del mundo, se ve arrastrado a querer justamente la más alta humanización”. ${ }^{46}$

${ }^{45}$ N. I, p.276.

${ }^{46} \mathrm{Ibid}$. , p. 285. Pero vayamos hasta el fin de este proceso de humanización inaugurado con la concepción cartesiana del mundo. Una de las cuestiones fundamentales que atañen al pensamiento contemporáneo radica precisamente en aquello que tanto Juliana González como Adolfo Sánchez Vázquez llaman la crisis del humanismo y que, como ejemplo de esta fuerza irredenta, nos muestran el pensamiento de Heidegger como la forma más depurada del antihumanismo. Que Heidegger sea antihumanista, de eso no puede caber la menor duda. El problema radica en dar cuenta de las variadas razones que llevaron al pensador de la Selva Negra a esta posición. Para Heidegger, la Carta sobre el humanismo, sólo representa un paso más en su discusión con el pasado filosófico dominado por lo que él llama metafísica y que, en términos generales, ésta se ha considerado como la auténtica filosofía, la pregunta por el ente como tal; aún en su versión vulgar y común conserva un resto de su significado nuclear: la metafísica pregunta por lo último, por lo que está más allá de la perspectiva habitual, por lo inaprehensible. En cualquier caso lo que prevalece es la inseguridad y la oscuridad. No se sabe qué es la metafísica, como señala Heidegger en Der Satz vom Grund, ella se presenta más bien como un límite y frontera, más allá de la cual todo es indeterminado y problemático. Ya en escritos anteriores a la Carta sobre el 
En esto habría consistido la inestimable aportación de Nietzsche, al mismo tiempo que sus indudables limitaciones: en haber dado una representación metafísica del hombre a escala de nuestro mundo actual. Por ello, la ciencia moderna, se convirtió en un manipular, elaborar e intervenir en la realidad. Pero precisamente por su carácter interventor, la ciencia moderna provoca y acosa a la realidad hacia su universal objetivación, que no es otra cosa que tener al mundo a nuestra disposición.

Esta forma de humanismo, a la que tanto Heidegger como Nietzsche tratan de superar, queda, en el segundo, envuelta por ese afán de superar el nihilismo, pero éste es destino del ser y rasgo de su historia. En su auto-ocultación, el ser se vincula con el olvido: "El olvido no afecta la esencia del ser únicamente en cuanto algo aparentemente distinto. El olvido es consustancial al ser. Reina como destino de su esencia”. ${ }^{47}$ Nietzsche, para Heidegger, pertenece a este destino y a esta historia. Su filosofía es la máxima expresión del nihilismo, pero Nietzsche no llega a superar el nihilismo. A la pregunta de su ensayo Nietzsches Wort "Gott is tot” — ¿comprendió Nietzsche la esencia del nihilismo?_- Heidegger contesta negativamente. El filósofo de Basilea ha conocido como ningún otro pensador algunos aspectos del nihilismo, pero no ha penetrado hasta su esencia; ésta consiste en que, en la aparición del ente como tal, el ser ha brillado por su ausencia, o mejor, esa ausencia no ha brillado como tal: del ser y de su verdad no ha habido nada.

humanismo, Heidegger, alrededor de este problema, advertía que el diálogo con la historia de la ontología radicaba en una destrucción sistemática del pasado para llegar a las fuentes originarias en donde se vertieron las primeras experiencias del pensar, para de ahí marchar por el sendero de lo que hay que pensar y da qué pensar: el ser. Por ello, la Carta sobre el humanismo sólo significaba dar un paso más allá del pensar raciocinante que dejó de lado y como destino al ser. De ahí que Heidegger, en su búsqueda, en ese itinerario de reconstrucción, como lo llamaría años después Derrida, haya encontrado dos acontecimientos decisivos que se dieron con mayor nitidez e iluminaron la época en la cual se da la culminación de la metafísica: la modernidad, esto es, como se señaló líneas arriba, la objetivación del mundo y la subjetivización del hombre. Así, el humanismo no fue más que el primero de una secuencia de hechos y conceptos ligados entre sí como fueron los de razón, libertad, universalidad, objetividad, subjetividad, Dios, entre otros. La representación de la humanidad que asume el mundo moderno, dominado por la técnica (técnica que, como veremos más adelante, es también de origen cartesiano): el trabajador y la realidad concreta convertida en resultado y efecto de una operación. Esto es lo que expresa de manera condensada y resumiendo todo el movimiento de Nietzsche el siguiente pasaje de Contribución a la cuestión del ser: "La fuente de la donación de sentido, la previa o actual potencia que imprime su sello en toda cosa, es la forma en cuanto forma de una humanidad: 'la forma del trabajador'. La forma se apoya sobre los rasgos esenciales de una humanidad que en cuanto subjectum, reside en el fundamento de todo ente. No es cuestión aquí de la yoidad de un hombre singular, de la subjetividad de la yoidad. Se trata más bien de la presencia de un tipo humano (typus) que constituye la subjetividad definitiva. Esta subjetividad aparece con el cumplimiento de la metafísica moderna y se ofrece en el interior de esta metafísica”.

${ }^{47}$ N. I, p. 238. 
El verdadero error de Nietzsche procede de su desconocimiento del nihilismo. Como consecuencia de esto, todos los rasgos de su filosofía se inscriben en el ámbito del mundo contemporáneo y confirman el nihilismo metafísico inherente a este mundo, en lugar de superarlo. Ésta es la razón de que el superhombre y la voluntad de poder se encarnen efectivamente en el universo dominado por la técnica. No son más que expresiones metafísicas de la dominación ejercida por la humanidad de este mundo, instalada en el abandono del ser.

\begin{abstract}
La metafísica de Nietzsche no se limita únicamente a interpretar el ser a partir del ente en la orientación impuesta por la voluntad de poder, concebida como un valor, sino que llega incluso a interpretar pensar esta voluntad como principio de una nueva institución de valores. En este sentido se le revela también como aquello que hace posible la superación del nihilismo. Y es entonces justamente cuando el hundimiento absoluto de la metafísica en la inautenticidad del nihilismo es evidenciado por la voluntad misma de trascenderlo. De tal modo ocurre esto, que el hundimiento disimula su propia esencia, y así, bajo la forma de una reducción, no hace otra cosa que trasponer el nihilismo al plano del eficaz desencadenamiento de su de-esencia (Unwesen). ${ }^{48}$
\end{abstract}

La ausencia del ser, entendida ésta como olvido del ser, como decía, no le ha acontecido a la metafísica por casualidad ni por descuido ni por error; es propio del ser quedar impensado, solaparse y esconderse dentro de su verdad, quedar vedado y velado mientras se revela, y ocultar su misma ocultación; la patentización (des-ocultación) entraña ocultación, ello es la esencia del misterio. La metafísica es lo impensado del ser, precisamente porque se funda en el misterio del ser. La metafísica sería entonces destino, el destino del ser. Metafísica es una "época de la historia del ser".

El verdadero nihilismo no es la volatilización del ente, sino del ser; el día que sepamos escuchar el nihilismo en este tono y bajo estas profundas visiones reconoceremos que "ni las perspectivas económicas, ni las políticas, ni las sociológicas, ni las técnicas y científicas, ni siquiera las metafísicas y religiosas bastan para pensar lo que está pasando en esta edad mundial". ${ }^{49}$ Eso que nos falta por pensar no es algún trasfondo inaccesible, sino algo que está ahí, lo más próximo y que por lo mismo se pasa siempre por alto: el ser. ${ }^{50}$

\footnotetext{
${ }^{48}$ N. II, p. 301.

${ }^{49} \mathrm{UH}$, pp. 244-246.

${ }^{50}$ Ibid.
} 
La esencia del nihilismo no reviste apariencia catastrófica, no se presenta con caracteres destructivos y negativos en el ámbito humano, porque la esencia del nihilismo no es cosa del hombre y no le afecta directamente a él. Es cosa del ser, por lo mismo, afecta a la esencia del hombre. Nietzsche no logró superar el nihilismo porque no penetró hasta su esencia. Tampoco Heidegger. Para remontarse auténticamente por encima del nihilismo, comprender la esencia del ser en su movimiento de presencia y de ocultación, habría que comprender que lo que se esencializa en el nihilismo es el morar-en-ausencia del ser en cuanto tal. Este morar-en-ausencia consiste en la ocultación que se lleva a cabo a través de la historia del ser, a partir del ser mismo. Es la inextirpable presencia de la nada en el ser. Así, la incomprensión de la esencia del nihilismo conduce, en definitiva, a la incomprensión de la nada, del nihil.

\footnotetext{
Puede que la esencia del nihilismo resida en el hecho de que no se toma en serio la cuestión de la nada. En realidad, se rehusa desarrollar esta cuestión y se defiende obstinadamente el esquema de una alternativa asimilada desde hace mucho tiempo. ${ }^{51}$
}

No obstante, se puede decir que lo que Heidegger pretende es trascender el nihilismo por medio de una superación de la metafísica, pero ¿esto significa el rechazo y la radical negación de la metafísica? El problema presentado en estos términos saldría al encuentro de la complejidad de su pensamiento y del equívoco deliberadamente mantenido y relacionado con la naturaleza misma del objeto tratado. Por ello, podría decir que Heidegger no es un antimetafísico en el sentido en que podría entenderse, por ejemplo, los filósofos del siglo XVIII francés y Nietzsche en su seguimiento. O los filósofos de la primera mitad del siglo XX. Entregado al pensamiento del ser, Heidegger piensa necesariamente dentro del ámbito de la metafísica y como metafísico. Por ello, la superación de la metafísica debe ser entendida como el reconocimiento de su dignidad irremplazable; como una apropiación de aquello que se explica en Contribución a la cuestión del ser.

Aquí el equívoco se aclara, al tiempo que pone en evidencia su carácter de inevitable. En este texto, la relación del ser con el ente, su producción como destino en el interior de la historia de la metafísica, postula la noción de trascendencia, utilizado ya en Sein und Zeit y reemplazada por otra terminología. La noción destino de la trascendencia es utilizada para salvar la metafísica y mostrar

${ }^{51}$ N. II, p. 48. 
cómo en ella la no-verdad forma parte integrante de la verdad. La relación verdad no-verdad constituye también uno de los temas de La esencia de la verdad (1930), en donde señala:

En consecuencia, si la nada reina en la esencia del nihilismo y en el ser se inscribe la esencia de la nada; si, por otra parte, es el ser destino de la trascendencia, entonces la esencia de la metafísica se nos revela como el lugar de la esencia del nihilismo.

¿En qué consiste entonces la superación (Uberwindung) del nihilismo? En la apropiación (Verwindung) de la metafísica. He aquí el extraño pensamiento. A éste procuramos encubrirlo. Nuestra repugnancia sería menor si observásemos cómo este pensamiento implica que la esencia del nihilismo nada tiene de nihilista y cómo también no se despoja a la metafísica de su antigua dignidad por el hecho de que el nihilismo se acoja en el interior de su propia esencia. Desde este punto de vista, por tanto, es preciso reconocer que la superación de la metafísica no consiste en otra cosa que en el desvelamiento de una verdad latente desde el origen; es, con profundidad, la realización de aquello que a lo que la metafísica aspira:

\footnotetext{
Ésta es la razón de que el pensamiento que quiere responder a la apropiación de la metafísica debe comenzar por esclarecer la esencia de la metafísica. A causa de una tal tentativa, la apropiación de la metafísica se presenta en un principio como una superación de la metafísica que se contenta con dejar tras de sí la representación exclusivamente metafísica, a fin de conducir el pensamiento hacia espacios más libres que se abren cuando se "retorna” de la esencia de la metafísica. Pero con mucho más exactitud que acontece en la apropiación, y sólo en ella, es que la verdad de la metafísica retorna de modo expreso, revelándose entonces como perdurable verdad de una metafísica aparentemente repudiada. Esta verdad, justamente, es la esencia de la metafísica ahora reapropiada: su morada. ${ }^{52}$
}

En realidad, la antimetafísica de Heidegger no puede juzgarse desde Nietzsche. Si para Heidegger el pensador de Basilea permanece siendo metafísico, desde el punto de vista de Nietzsche, el metafísico es Heidegger. En conclusión, cuando afirma Heidegger pensar la verdad de la metafísica no hace otra cosa que asumir

${ }^{52}$ Ibid., p. 239. 
explícitamente la misión del metafísico. La confrontación del pensamiento de Heidegger con el de Nietzsche corresponde a uno de los momentos capitales del filosofar heideggeriano. En esta confrontación se ponen de relieve los límites del pensamiento del filósofo de la Selva Negra. Esto es innegable, y corresponde a otros pensadores poner de manifiesto estos desacuerdos planteados por la labor del pensar.

Finalmente, habría que celebrar la traducción de este excepcional libro que, como se puede advertir, es una de las formas con las que Heidegger se encontró para deconstruir la historia de la metafísica, al tiempo que revela el quehacer nietzscheano como la culminación de la metafísica y la preparación para el advenimiento de la técnica en el ámbito planetario. 